\title{
Sustainability Evaluation of Mass Customization
}

\author{
Thomas Ditlev Brunø, Kjeld Nielsen, Stig Brink Taps, and Kaj A. Jørgensen \\ Department of Mechanical and Manufacturing Engineering, Aalborg University, Denmark \\ tdp@m-tech. aau.dk
}

\begin{abstract}
This paper addresses the issue whether the concepts mass customization and sustainability are fundamentally compatible by asking the question: can a mass customized product be sustainable? Some factors indicate that mass customized products are less sustainable than standardized products; however other factors suggest the opposite. This paper explores these factors during three life cycle phases for a product: Production, Use and End of Life. It is concluded that there is not an unambiguous causal relationship between mass customization and sustainability; however several factors unique to mass customized products are essential to consider during product development.
\end{abstract}

Keywords: mass customization, sustainability, remanufacturing.

\section{Introduction}

Mass customization (MC), popularized by Pine et al. have proven a successful business strategy in various industries markets and for several different product types [10]. Mass customization is different from mass production in several different ways, including product design and production to sales and marketing and fit with customer needs.

Sustainable development is defined by the Brundtland Commission as "a development that meets the needs of the present without compromising the ability of future generations to meet their own needs" [4]. Sustainable development includes three dimensions: the environmental, economic and social dimensions [4]. However, in this study it is chosen to focus on the environmental dimension of sustainability.

Sustainability is a concept that is gaining more and more attention, and companies are experiencing a greater demand for sustainable products. Several concepts are applied to achieve greater sustainability in product design and manufacturing. Among these is Eco-design, which is a concept that attempts to integrate environmental aspects into the product development process thereby creating products with lower negative environmental impacts and thus more environmentally sustainable products. Since mass customizing companies, just like every other company, will have to consider sustainability, it is relevant to consider how mass customized products are different from mass produced products in a sustainability perspective. 


\section{Research Method}

The research objective of this paper is to identify mechanisms in mass customization, which can yield mass customized products more sustainable or less sustainable compared to traditionally mass produced products. The research question is: "How can the elements of mass customization influence the environmental sustainability of a product?" To answer this question, it must first be clarified which elements of mass customization are addressed in this context. Secondly the concept of environmental sustainability must be clarified. Finally the interrelations between these two concepts are identified and analyzed. To structure this analysis, the interrelations are grouped according to the product life cycle. Rose [11] presented a generic product lifecycle, which is illustrated in figure 1.

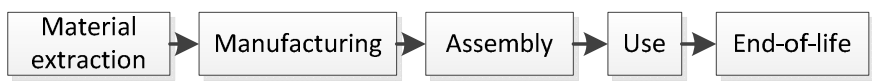

Fig. 1. Generic representation of a product life cycle (Rose, 2000)

The first stage, materials extraction and processing, is not expected to have strong relations to whether a product is mass produced or mass customized and this stage is thus disregarded in this paper. Furthermore, the manufacturing and assembly stages are joined into one stage. The analysis is thus divided into the following phases of a product lifecycle: 1) Production, 2) Use and 3) End of Life. For each of these phases, mass customization and mass production products are compared.

Within the first two areas, production and use, the analyses are structured on basis of concepts which are characteristic for mass customization production and products. More specifically, the factors described by Berman [2] and Maccarthy [8] have been reviewed and those which were found to have relevance for this study have been included: 1) Product Modularity, 2) Process Variety, 3) Distribution Channels, 4) Improved fit with customer needs \& 5) Product functionality customization.

Furthermore, concepts which have their origin in sustainability research have been identified through literature studies. The concept of reducing energy consumption, which is essential in eco design as well as life cycle thinking [6], is included as well. In the End of life stage, a number of end of life strategies identified by [11] are included in the elements which are analyzed: 1) Energy efficiency, 2) Reuse, 3) Service, 4) Remanufacturing, 5) Recycling and disposal. In the following, the elements presented above and their relations will be analyzed.

\section{Analysis}

\subsection{Production}

Modularity is usually considered a key enabler for efficient mass customization [10] and thus most producers of mass customized durables apply modular product architectures. Ulrich et al. describe modular product architecture as the opposite of an 
integral architecture [12]. The advantages of an integral architecture are usually that the performance of a product can be improved compared to a modular product. In this context, the performance could among other things be properties like size and weight. It is generally acknowledged to be good practice in EcoDesign to minimize usage of material resources in manufacturing [7]. Since mass customized products are usually modular and following the arguments from Ulrich et al. [12], it could be expected that more material resources are necessary to produce those compared to mass produced products, since modular products cannot be optimized with regards to weight and thereby material usage as mass produced products. This is assuming that the mass produced product is optimized for minimum material resource usage by applying integral product architecture. Hence, mass customized products may have a greater environmental impact during production due to a higher material usage.

In relation to process variety, mass customization requires much higher process flexibility compared to mass production due to the higher product variety and subsequently process variety [2]. The fact that many more different manufacturing processes are necessary to product customized products compared to standard products makes it more difficult to optimize the processes with respect to energy and material consumption. Hence the fact that the process variety is higher in mass customization may imply a greater environmental impact than mass production.

An element of mass customization which differentiates it significantly from mass production is the distribution channels. In mass production, a finished product may be distributed through several tiers of distributors before being purchased and taken to the final customer. In contrast to this, mass customized products are produced for one specific customer and are thus possible to distribute directly from producer to end customer. This could serve as an argument for mass customization to have both a higher and lower environmental impact compared to mass production in relation to distribution.

The argument for a higher environmental impact would be that each product is distributed individually from manufacturer to customer, which would require more packaging and presumably more energy, since each product would take more space compared to a larger number of similar standard products, which could be packaged and distributed together. The argument for a lower environmental impact would be that the product does not travel through multiple tiers of suppliers and thus is expected to have a shorter route from producer to consumer which could again be expected to consume less energy and fewer emissions.

Finally, to be able to deliver a mass customized product to the customer within an acceptable time, it can be beneficial to produce the product closer to the customer than for mass produced products. The reason for this is that mass produced products can be produced geographically far away from the customer, but given they are standard products, they can be kept in stock close to the end customer. This is of course not possible for customized products and this distribution strategy is thus not feasible for mass customization. This is a reason why mass customized products are more likely to be produced close to the end customer than mass produced products and as a consequence the product has to travel a shorter distance from producer to end customer yielding lower energy consumption in the distribution. 


\subsection{Use}

When a customer chooses to purchase a mass customized product, this will most likely provide an improved fit between the product's properties and the customer's needs [2], compared to purchasing a standard product.

For certain groups of mass produced products, the purchase price is so low that consumers do not hesitate to dispose a nearly unused product if it does not meet the customer's needs and purchase a replacement, assuming that it will better fit the needs. However, this will likely produce extra negative environmental impacts, since the product reaches its end-of-life before it has worn out. One example of this from the apparel industry is presented by Hethorn et al. [5]. Much apparel is so inexpensive that many customers purchase clothing which may not fit. Clothes that do not fit are unlikely to be worn by the customer, and the resources for producing those clothes are thus wasted, and the resources for producing clothes for that customer, from an overall perspective, could be reduced.

Creating products that have a better fit with the customers' needs could thus reduce the waste that is produced by manufacturing products that are never used. Mass customization presents an opportunity to do just that, since the better fit that customers achieve by choosing a mass customized product would logically reduce the probability that the product is not used and that the resources used for manufacturing it are thus wasted. This goes not only for apparel but for other product types as well which have a cost low enough for customers not to hesitate disposing even an unused product if it does not fit their needs. Hence the mechanism that mass customization provides a better fit introduces an opportunity that mass customization products could reduce the type of waste presented above.

In relation to production it was described above that integral product architecture would usually yield a greater potential for optimizing the product with respect to performance compared to modular product architecture. One other aspect where this is relevant in relation to environmental impact is the energy efficiency, which obviously is only relevant for those durables that consume either electricity or other energy sources. Given that most mass customized products are modular; this is another mechanism that could render mass customized products less environmentally sustainable than mass produced products which have the potential of being more optimized for energy consumption than mass customized products.

There is however an argument which could counter this mechanism. Applying modular product architecture, most companies would attempt to establish modules which are standardized across multiple products. This would then imply that the company due to the larger volume could, invest larger sums in optimizing that particular module thus potentially achieving greater energy efficiency than a mass produced product, given that module is was is produced in larger numbers than individual mass produced variants.

\subsection{End of Life}

Rose [11] presented the hierarchy of end-of-life (EOL) strategies which is illustrated in figure 2. Generally, in order to minimize the environmental impact at product end 
of life, strategies higher in the hierarchy should be chosen. Strategies 1-5 are so called closed loop strategies [1], and are preferable to open loop strategies (6), since they make use of the value and resources already added to the raw materials [11]. End-oflife in this context is defined as the point in time where the original user does no longer wish to use the product for whatever reason.

Shorter loops and smaller environmental impact

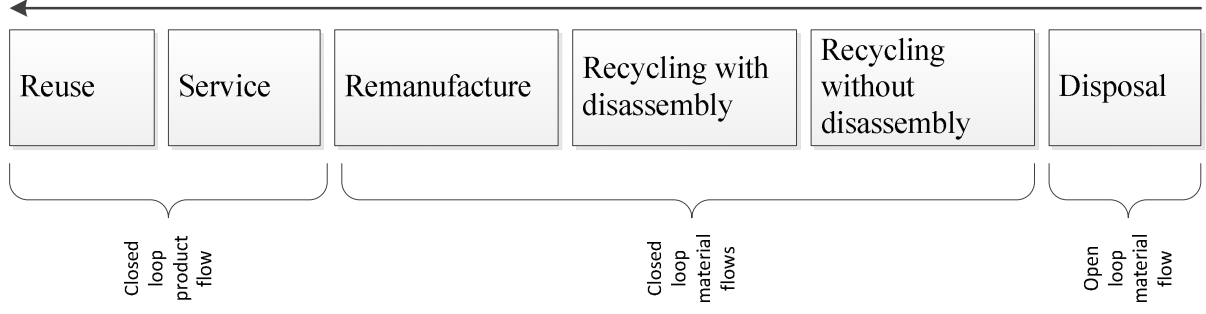

Fig. 2. Hierarchy of End-of-life strategies from [11]

The EOL strategy reuse implies that the product at EOL is obtained and used by a new user without modifying or refurbishing the product. This strategy implies no consumption of resources and makes it unnecessary to manufacture a new product thus reducing the resources needed to fulfill the customers' needs. Considering this strategy in relation to mass customization presents a critical issue: Since mass customized products are tailored to an individual customer's requirements, it is unlikely that the product's properties will fit an entirely different customer's requirements, since those requirements would need to be uniform. For example it is unlikely that for example a T-shirt customized with some personal information, e.g. a photo or a name would be worn by someone else than the original buyer. Hence we can conclude that there is potential complication in designing a mass customized product that can be "reused" in their original form. There are however mechanisms which can counter this issue. If mass customization of a product is achieved by designing a selfcustomizing product as presented by Alhstrom et al. [1], a new user of the product would simply re-configure or re-personalize the product to meet the new requirements. Hence, it cannot be unambiguously concluded that mass customized products cannot be re-used and therefore be optimal in relation to their EOL environmental impact.

If a product is to be replaced due to "wear and tear", i.e. the product is somehow worn or defective and thus cannot be reused, which is the preferred EOL strategy according to the hierarchy, the strategy "service" should be considered [11]. In this strategy, the life of a product is extended by repairing or servicing the product thus pushing the time where a new product will have to be manufactured to fulfill a user's needs. There is no apparent and strong relation between this strategy and mass customization, however the variety of parts included in the product may cause some issues if spare parts are necessary. This would be the case if the parts, which are to be replaced to repair the product, are custom fabricated, as opposed to a customized product assembled from standard components. If a custom fabricated component is required for repairing or servicing the product, this would likely be more expensive than 
repairing a product using standard components, since the spare part would need to be manufactured specifically for that product which would likely introduce higher logistical costs as well as a problem regarding the identification of specifications for manufacturing that specific part. Many mass customization products are designed using modular product architecture to be able to efficiently manufacture custom products. The nature of a modular product would likely enable upgrading the product, given that upgrading possibilities has been considered when defining the product architecture. Comparing this to a standard product, which may not have a modular architecture which is prepared for replacing or adding modules, the modular mass customization product would be possible to upgrade compared to a standard product, where modules with variety are not readily available.

The third level of the hierarchy, remanufacturing implies, as well as the two recycling levels, the closed loop material flows in the hierarchy [11]. Remanufacturing is defined by Nasr et al. [9] as: The process of disassembling, cleaning, inspecting, repairing, replacing, and reassembling the components of a part or product in order to return it to "as-new" condition. As described above, many mass customized products will have modular product architecture. Modular products can generally be expected to be more appropriate for disassembling compared to integral products [3]. It should be noted in this context, that this relationship is based on the product architecture (modularity) and not the customization of the product. Hence this relationship can also be applicable for standard products given they are based on a modular architecture.

Many mass customized products are configured using configurator software and a specific configuration can be traced to a specific customer. This implies that the manufacturer is likely to have knowledge of exactly which customers do have a product that can be taken back for remanufacturing thus enabling companies to provide incentives to the customer for returning and EOL product. Using remanufacturing as an EOL strategy for mass customized products, products can be disassembled into modules which are stored and reassembled to new products configured to match a new customer's requirements. As for the service EOL strategy, custom fabricated components complicate this strategy since it may not be possible to remanufacture these and hence must be recycled, which is less desirable. It can thus be concluded that remanufacturing is likely to be a good EOL strategy given the mass customized product is not self-reconfiguring and does not contain custom fabricated components.

In levels 4 and 5, EOL strategies are less desirable than the strategies where the entire product is reused, however preferable to disposal. Mass customized products are often modular and thus easier to disassemble than standard products which are more likely to be non-modular. This is of course relevant for the "Recycling with disassembly" EOL strategy. Furthermore, modular product architecture will enable concentrating certain material fractions in certain modules which will likely increase the recyclability.

\section{$4 \quad$ Analysis of Results and Implications}

The results of the analyses performed in section 3 are summarized in figure 3 . As it can be seen from this figure there are several relations between the elements of mass customization and environmental sustainability that indicate that mass customization 
does have an effect on the sustainability of a product. In figure 3 , the boxes above the dashed line represent concepts which are typically addressed by researchers and practitioners within mass customization, whereas the boxes below the line represent the elements of sustainability that were found to have a relation to mass customization.

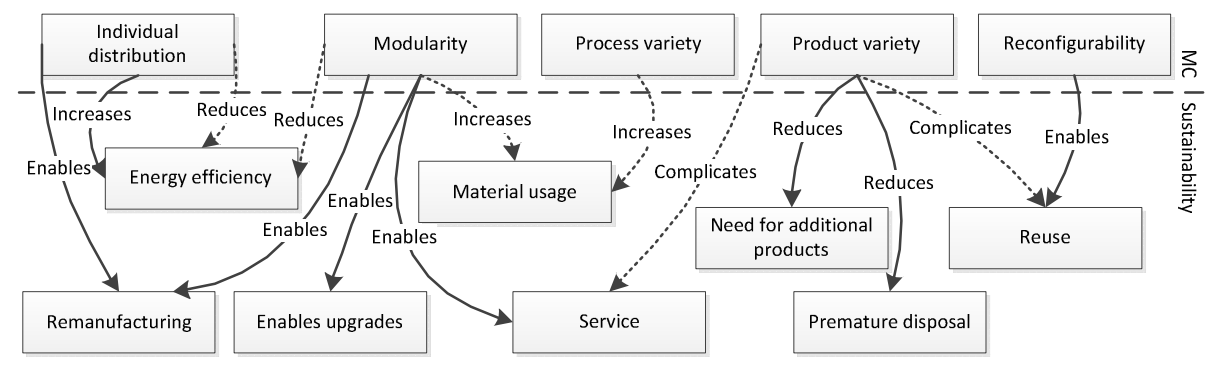

Fig. 3. The relations between mass customization and sustainability

The dotted arrows from the mass customization concepts to the sustainability concepts represent the identified relationships where mass customization potentially has a negative influence on sustainability compared to mass production. The solid lines are opposite and represent relationships where mass customization can be expected to be more sustainable than mass production. Eight positive relationships and six negative relationships were identified; however these numbers cannot be used for concluding that mass customization is more sustainable than mass production, since these relations are not unambiguously quantifiable, since they can only be quantified for specific products, as different products will have different environmental impacts. What is also interesting is that not several single elements of mass customization potentially have both negative and positive effects on sustainability compared to mass production. One example of this is the individual distribution, which can have both negative and positive impact on the energy efficiency during distribution.

This finally implies that the assessment of whether mass customized products are more or less sustainable than similar mass produced products will depend entirely on individual studies. Consider two completely different products; an automobile and a piece of clothing. The environmental impact profiles of these two products are completely different. The automobile will consume much more energy throughout the use phase of its lifecycle than consumed during product phase, whereas a piece of clothing will consume no energy during its lifecycle. Furthermore, an automobile is much more likely to be serviced to extend its life cycle and to be reused when its original purchaser disposes of it. Hence, the difference between mass customized and mass produced products will vary greatly between these two groups of products.

From the results of the analysis in section 3 there is no indication that mass customization should have the potential to be less sustainable than mass production. The results presented can thus be used as guidelines for how to address sustainability issues in mass customization by pointing out areas where mass customization is different from other business strategies, thereby assisting in tailoring strategies for becoming more sustainable. 


\section{Conclusion}

It can be concluded that there are indeed many elements of mass customization which can influence the environmental sustainability of a product if it is compared to a similar mass produced product. However, since there are both factors which contribute more sustainable and less sustainable products, a universal conclusion cannot be drawn for all mass customized products. It can thus be concluded that mass customization it not either sustainable or unsustainable, but has indeed the potential to contribute to sustainability.

The work presented in this paper is a qualitative study to explore the links between mass customization and sustainability. Further research could analyze these relations using a quantitative approach for specific product types to analyze the relations in specific cases.

\section{References}

1. Ahlstrom, P., Westbrook, R.: Implications of Mass Customization for Operations Management: An Exploratory Survey. International Journal of Operations \& Production Management 19, 262-275 (1999)

2. Berman, B.: Should Your Firm Adopt a Mass Customization Strategy? Bus. Horiz. 45, 51-60 (2002)

3. Bogue, R.: Design for Disassembly: A Critical Twenty-First Century Discipline. Assem. Autom. 27, 285-289 (2007)

4. Brundtland, G.H.: World Commission on Environment and Development. Our Common Future (1987)

5. Hethorn, J., Ulasewicz, C.: Sustainable fashion: Why now. Fairchild Publications, Inc., New York (2008)

6. Kørnøv, L., Lund, H., Remmen, A.: Tools for a sustainable development. Institut for Samfundsudvikling og Planlægning. Aalborg Universitet (2005)

7. Luttropp, C., Lagerstedt, J.: EcoDesign and the Ten Golden Rules: Generic Advice for Merging Environmental Aspects into Product Development. J. Clean. Prod. 14, 1396-1408 (2006)

8. Maccarthy, B.: Understanding Customization in Mass Customization. IEE Seminar Digests, 1 (2003)

9. Nasr, N., Thurston, M.: Remanufacturing: A Key Enabler to Sustainable Product Systems. In: Proceedings of LCE. 13th CIRP International Conference in Life Cycle Engineering, pp. 15-18 (2006)

10. Pine, B.J.: Mass customization: The new frontier in business competition. Harvard Business School Press (1993)

11. Rose, C.M.: Design for environment: A method for formulating product end-of-life strategies. In: Design for Environment: A Method for Formulating Product End-of-Life Strategies. Stanford University (2000)

12. Ulrich, K.T., Eppinger, S.D.: Product design and development. McGraw-Hill, New York (2004) 